macaques despite reporting that the species frequently raids their crops and that lethal traps are sometimes set for the macaques. These findings are in contrast to those for Sulawesi, where macaques are a favoured bushmeat species.

Our findings are limited by the briefness of our visit but indicate that a substantial population of $M$. nigra persists in central Bacan. If this situation is similar in northern and southern Bacan, as appears to have been the case in the 1990s, then the population of M. nigra on Bacan probably exceeds that in its native range. The Bacan population also appears to be less directly threatened than in Sulawesi. We recommend monitoring of the Bacan population to establish the impacts of any threats and to investigate any potential genetic effects of the presumably small number of founders.

The case of M. nigra on Bacan is unusual: a species that is Critically Endangered in its native range appears to have a much larger, potentially less threatened population hundreds of kilometres away as the result of an undocumented introduction. The role of this population for the conservation of the species warrants careful consideration, and the species' abundance, ecological impact and genetic status on the island requires further research.

The Bacan expedition was undertaken by Selamatkan Yaki, an initiative dedicated to the conservation of M. nigra and its habitat, and was funded by the North of England Zoological Society-Chester Zoo, with additional support from the Whitley Wildlife Conservation Trust and Taronga Conservation Society Australia.

HarRy Hilser, Yunita Siwi, IsMail Agung and Gaetan Masson Pacific Institute for Sustainable Development-Selamatkan Yaki, Manado, Sulawesi Utara, Indonesia.E-mail harry@ selamatkanyaki.com

AndREW BowKett and Amy B. PLowman Whitley Wildlife Conservation Trust, Paignton, UK

VICKY Melfi TaRonga Conservation Society Australia, Mosman, New South Wales, Australia

JOHN S. TASIRIN University of Sam Ratulangi Manado, Manado, North Sulawesi, Indonesia

\section{Mystery of giant rays off the Gaza strip solved}

There have been recent reports of an apparent mass stranding of dozens of the Endangered large devil ray Mobula mobular on beaches of the Gaza Strip in Palestine (Daily Mail, 27 February 2013). This species is categorized as Endangered on the IUCN Red List and is likely to be the rarest of the nine species of Mobula. There was much public and scientific speculation about the causes of the stranding. Cetaceans can strand as a result of the sonar activity of ships and submarines but there is no evidence that elasmobranchs, the group that includes Mobula, are affected by such activities. A mass stranding or disease are improbable because elasmobranchs are negatively buoyant and thus do not generally wash up on beaches. Suspicions about the cause of the deaths were raised by video footage (published online by the Daily Mail) of local people on the beach cutting out the gills, removing fins and filleting the rays, with some proficiency.

It has now been confirmed by $\mathrm{Dr}$ Mohammed Abudaya (United Nations Relief and Works Agency), through Professor Dani Kerem (University of Haifa) and Dr Notarbartolo-di-Sciara (Tethys Research Institute) that this was a fishery operation. Palestinian fishermen, recently allowed to fish up to 7 nautical miles offshore, noticed a large aggregation of M. mobular at the surface in an area close to the Egyptian border on 26 February 2013. They caught about 500 rays weighing 150-250 kg each. Dr Argyris Kallianiotis (National Agricultural Research Foundation) mentioned in a message sent to the Italian Society for Marine Biology that M. mobular was considered a valuable species for the local fish market. Local fishermen described the importance of the M. mobular fishery, which is conducted around the end of February each year, during a visit by FAO experts earlier this year. This species receives some protection in the Mediterranean Sea as it is listed under Annex II of the Barcelona Convention and Appendix II of the Bern Convention but the Gaza Strip is not a signatory to either of these. Waters off this region appear to be an important aggregation site for M. mobular. Our concern is that even before we understand the reasons for what appears to be a large seasonal aggregation, whether for reproduction or feeding, it could be lost.

Lydie I.E. Couturier and Michael B. BeNNetT School of Biomedical Sciences, The University of Queensland, St Lucia, Queensland, Australia.E-mail l.couturier@uq.edu.au

ANTHONY J. RichaRDSON Climate Adaptation Flagship, CSIRO Marine and Atmospheric Research, Brisbane, Queensland, Australia, and Centre for Applications in Natural Resource Mathematics, School of Mathematics and Physics, The University of Queensland, St Lucia, Queensland, Australia

\section{Curtailment of run-of-the-river power projects brings respite to the Western Ghats}

Public resistance to large hydroelectric dams in India has compelled the government to provide subsidies for so-called green energy projects, such as run-of-the-river power generation. Such works, popularly referred to as minihydel projects, are increasing in number and are potentially threatening wildlife and habitats. One area where minihydel projects are being implemented is the Western Ghats 